\title{
DEVELOPMENT AND VERIFICATION OF A SHOCK ABSORBER AND ITS SHIM VALVE MODEL BASED ON THE FORCE METHOD PRINCIPLES
}

\section{MODELOWANIE I OCENA AMORTYZATORA I JEGO ZAWORU TALERZOWEGO OPARTE NA ZASADACH METODY SIt}

\begin{abstract}
In this paper, a mathematical model of a monotube shock absorber's shim valve, which is developed by applying the force (flexibility) method, is described. This method expresses the relationship between displacements and the forces existing in the shock absorber structure. An application of the force method in the field of practical modification of vehicle shock absorbers enables to effectively analyse the influence of a wide range of parameters, including the number of shims in the valve, their disposition and the properties of the material on the level of the damping force. The damping of the shock absorber considerably impacts comfort and road holding characteristics of the vehicle. In addition, a whole model of a monotube shock absorber is designed in this paper. The validation and practical application of the mathematical model were evaluated by carrying out experimental measuring of the characteristics of the shock absorber using a special stand.
\end{abstract}

Keywords: damping characteristics, force method, mathematical model, monotube, shock absorber, shim valve.

\begin{abstract}
W danej publikacji zostat opisany model matematyczny zaworu talerzowego jednorurowego amortyzatora, wyprowadzenia którego zastosowano metodę sit. Metoda ta wyraża związki pomiędzy przemieszczeniami i siłami działajacymi na elementy amortyzatora. Stosowanie metody sit w praktycznej sferze modyfikacji amortyzatorów samochodowych pozwala efektywnie analizować wptyw różnych parametrów, w tym ilość, wzajemne położenie $i$ właściwości materiałów talerzy zaworu, na generowanq amortyzatorem wielkość sity thumienia. Ttumienie, które generuje amortyzator, wywiera znaczacy wpływ na komfort jazdy samochodem oraz jego dynamikę. W publikacji również zostat stworzony kompletny model jednorurowego amortyzatora. Walidacja modelu matematycznego oraz możliwość zastosowania jego w praktyce zostaty ocenione na podstawie eksperymentalnych pomiarów charakterystyk amortyzatorów na specjalnym stanowisku.
\end{abstract}

Stowa kluczowe: charakterystyka tlumienia, metoda sit, model matematyczny, amortyzator jednorurowy, zawór talerzowy.

\section{Introduction}

When a vehicle moves over road irregularities, the appearing oscillations of sprung and unsprung masses negatively affect the driving dynamics and safety [29]. Seeking to improve road holding and normal component of the tire/ground contact forces during various manoeuvres, acceleration and braking, it is necessary to determine precisely the damping characteristics of the modified shock absorber and to control them. It is practically impossible to experimentally evaluate the damping characteristics of shock absorbers, which are obtained upon applying various combinations of a modified shim valve and its shims, due to high costs and considerable time input [1]. It is an actual problem faced while designing shock absorbers for sports cars, so mathematical modelling is an alternative to experimental tests. Taking into account the above-described reasons, the aim of this paper is to develop a mathematical model of a monotube shock absorber with a shim valve, which can be applied in practical activities.

\section{Background}

Research works on the interaction between a shock absorber and a suspension $[4,5,9,12,20,24]$ prove it to be a relevant problem which has great influence on the dynamic stability of the vehicle. Neverthe- less, the literature $[7,8,25]$ point out that researches on the functional dependencies of damping characteristics on shock absorber and its shim valve properties are highly limited, i.e. the mentioned researches are focused on the impact of the absorber's properties on the suspension of the car and movement of the car and not on the influence of structural elements of the shock absorber on its damping properties.

The first mathematical model of a shock absorber based on experimental researches was presented by H. Lang in 1977 [14]. H. Lang used an 82-parameter analogue computer model that provided good realistic results; however, the designed model was insufficiently developed for investigation of functional dependences of various input parameters. In 1994, K. Reybrouck presented a simplified model of a shock absorber formed of 20 variables. The proposed model was based on the method of semi-empirical coefficients, so it did not consider the effect of internal modifications on shock absorber performance $[1,21]$. In 1997, K. Lee presented a mathematical model of a monotube shock absorber. Accurate agreement between the model results and test data were achieved for shock absorber rod velocities up to $\pm 1 \mathrm{~m} / \mathrm{s}$. In the work presented by K. Lee, the impact of a disc valve on damping characteristics is discussed and the finite element method is applied to obtain solutions for the disk valve; however, a shim valve is not analysed [15]. M.S. Talbott designed a mathemati- 
cal model of a monotube shock absorber for sports cars that includes a detailed model of a disk valve and a partial discussion of a shim valve [26]. The model proposed by M.S Talbott is used and improved in the literature [22]; however, a specific model of a shim valve is not provided. Nevertheless, in both above-mentioned works, it is proposed to apply Roark's formulas for stress and strain for calculation of deformation of a shim valve; in addition, an application of the superposition principle in the process of shim valve modelling is discussed. Linear and nonlinear models of a shim valve based on the principles of the finite element method, which evaluate the geometrical dimensions of the shims and the properties of the material, are presented in [6]. In this source, the results obtained on applying a linear model and a nonlinear model are compared between each other, their differences, complexity, variables of models are discussed; however, the results obtained on applying the mentioned models are not compared to the results obtained during experimental tests. It is indicated that the simulation time while applying the designed advanced model may take up to 16 hours. In [8], it is proposed to apply the principle of minimum potential energy and Rayleight-Ritz method for modelling a shim valve. Nevertheless, it is pointed out that a large amount of computation must be performed that is not necessary; however, there is no way to find the shim stack tip deflection without solving for all the unknown coefficients. This takes a long time and reduces the overall speed of the shock absorber model code. Y. Ping also designed mathematical models of monotube shock absorbers and examined the influence of the structures of absorbers on their damping characteristics. However, the problems dealt with by the author are not related to the structure of the valves $[18,19]$, and discrepancies, which were explained by the ignorance of physical properties of the oil (Oil Bulk modulus), were noticed during the model validation. The influence of the technical condition of structural elements of the shock absorber on its exploitation and damping characteristics is examined in literature $[2,3,4,11,13,28]$ as well. It can be seen from the provided examples that various research works, where the influence of the structure of a shock absorber on its damping characteristics is discussed, are published; however, in such works, including the reviewed ones, seeking to simplify the process of modelling, various simplifications are made and they predetermine inexact results of modelling or the models becomes too complicated and not ready for practical application. Because of these reasons, the designing of new more accurate mathematical models developed for practical application is a relevant task. The model presented in this paper distinguishes itself from other shim valve mathematical models by the principle of its developing upon applying the force method based on the examination of the interaction between shims and the appearing contact forces.

\section{Mathematical model}

\subsection{Monotube shock absorber mathematical model}

The scheme, based on which the general mathematical model of the monotube shock absorber is designed, is presented in Fig. 1.

In literature $[8,15,18,26]$, it has been shown that the chambers pressures depend on numerous parameters, including the shock absorber stroke and velocity. Under isothermal conditions, the pressure

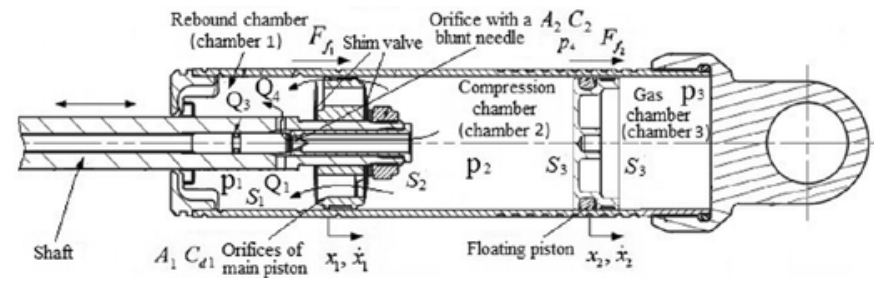

Fig. 1. The scheme of the modelled monotube shock absorber presenting its structure and main parameters changes in the rebound chamber (the chamber 1 (Fig. 1)) and the compression chamber (the chamber 2 (Fig. 1)) are found from the continuity equations:

$$
\begin{gathered}
\frac{d p_{1}}{d t}=\frac{E}{V_{10}+S_{1} x_{1}}\left(\left(Q_{1}+Q_{2}+Q_{3}+Q_{4}\right)-\left(S_{1} \dot{x}_{1}\right)\right) \\
\frac{d p_{2}}{d t}=\frac{E}{V_{20}+S_{3} x_{2}-S_{2} x_{1}}\left(\left(-Q_{1}-Q_{2}-Q_{3}-Q_{4}\right)-\left(S_{3} \dot{x}_{2}-S_{2} \dot{x}_{1}\right)\right) .
\end{gathered}
$$

where $E$ is Oil Bulk modulus, MPa; $V_{10}$ and $V_{20}$ are the initial volumes of the rebound and compression chambers, $\mathrm{m}^{3} ; Q_{\mathrm{i}}$ is the oil flow rate of corresponding orifices, $\mathrm{m}^{3} / \mathrm{s}$ (the amount of orifices depends on the construction of the shock absorber, their indexes are explained further in this section (Fig. 1)); $S_{i}$ is the cross-section area of the relevant chamber, $\mathrm{m}^{2} ; \dot{x}_{1}$ is the velocity of the main piston, $\mathrm{m} / \mathrm{s} ; \dot{x}_{2}$ is the velocity of floating piston, $\mathrm{m} / \mathrm{s} ; x_{1}$ is the displacement of the main piston, $\mathrm{m} ; x_{2}$ is the displacement of the floating piston, $\mathrm{m}$.

Assuming the adiabatic process, the pressure change in the gas chamber (the chamber 3 (Fig. 1)) is expressed as follows:

$$
\frac{d p_{3}}{d t}=-\frac{\gamma p_{3} \cdot\left(-S_{3} \dot{x}_{2}\right)}{V_{30}-S_{3} x_{2}}
$$

where $V_{30}$ is the initial volume of the gas chamber, $\mathrm{m}^{3} ; x_{2}$ is the displacement of the floating piston, $\mathrm{m} ; S_{3}$ is the cross-section area of the gas chamber, $\mathrm{m}^{2} ; \gamma$ is the gas adiabatic constant; $p_{3}$ is the gas chamber pressure, $\mathrm{Pa}$.

Eq. 1-3 are the first order coupled ordinary differential equations for $p_{1}, p_{2}, p_{3}$ and the Dormand-Prince integration method was used to solve these equations. The oil flow rate through the main orifices of the main piston $\left(Q_{1}\right)$, the additional orifices of the piston $\left(Q_{2}\right)$ and the variable orifices $\left(Q_{3}\right)$, is determined by applying the following expression:

$$
Q_{i}=C_{d i} \cdot A_{i} \cdot \operatorname{sign}\left(p_{2}-p_{1}\right) \cdot \sqrt{\frac{1}{\rho}\left(p_{2}-p_{1}\right)},
$$

where $C_{d i}$ is the discharge coefficient; $A_{i}$ is the cross-section areas of the orifices intended for compression or rebound strokes, respectively, $\mathrm{m}^{2} ; \rho$ is the density of oil, $\mathrm{kg} / \mathrm{m}^{3}$.

Eq. 4 is not suitable for discharge calculation when the oil leaks between the piston Teflon band and the cylinder of the shock absorber. According to the literature $[14,26]$, the leakage between the piston Teflon band and the cylinder wall $\left(Q_{4}\right)$ can be modelled as a flow between two parallel plates. The equation for the flow between two parallel plates is derived from the Navier-Stokes equations:

$$
Q_{4}=\left(\frac{\left(p_{2}-p_{1}\right) b^{3}}{12 \eta l}+\frac{\dot{x}_{1} b}{2}\right) \cdot \pi \cdot D_{p},
$$

where $b$ is the width of the gap between the piston Teflon band and the cylinder of the shock absorber, $\mathrm{m}$; $l$ is the length of the gap between the piston Teflon band and the cylinder of the shock absorber, $\mathrm{m} ; D_{p}$ is the diameter of the piston, $\mathrm{m} ; \eta$ is the dynamic viscosity of oil, $\mathrm{mPa} \cdot \mathrm{s}$.

The discharge coefficient is strictly a function of Reynolds number, piston acceleration and the geometry $[7,8,15]$. In this study, the dis- 
charge coefficients are assumed to be geometry dependent only. In addition, it is assumed that the discharge coefficient is constant and was chosen such that the maximum agreement between the experimental tests' data and the mathematical model is achieved. However, different values were used for compression and rebound since the geometry around orifices is not symmetric. The optimum value of the discharge coefficient for variable diameter orifices during compression is 0.65 , during rebound -0.48 . The tested shock absorbers are in excellent working condition, so the oil loss discharge is not modelled.

The dependence of the dynamic viscosity of oil on temperature is evaluated by applying Vogel-Tamman-Fulcher type equation [10]:

$$
\eta=\eta_{0} e^{\frac{E_{0}}{R\left(T-T_{\eta}\right)}},
$$

where $\eta_{0}$ is the constant dynamic viscosity of oil determined at certain temperature $\mathrm{T}_{\eta}, \mathrm{mPa} \cdot \mathrm{s}$; e is Euler's number; $E_{0}$ is the oil molecules activation energy, $\mathrm{J} / \mathrm{mol} ; \mathrm{T}_{\eta}$ is the oil temperature at which the constant dynamic viscosity $\eta_{0}$ of oil was fixed, $\mathrm{K} ; T$ is the oil temperature during the experiment, $\mathrm{K} ; R$ is the ideal gas constant, $\mathrm{J} / \mathrm{mol} \cdot \mathrm{K}$.

The functional dependence of density on temperature is expressed as follows [7]:

$$
\rho=\frac{\rho_{0}}{1+\alpha\left(T-T_{t}\right)}
$$

where $\rho_{0}$ is the constant density of oil determined at certain temperature $T_{t}, \mathrm{~kg} / \mathrm{m}^{3} ; T_{t}$ is the oil temperature at which the constant density of oil $\rho_{0}$ was fixed, $\mathrm{K} ; \alpha$ is the coefficient of volumetric thermal expansion, $\mathrm{K}^{-1}$. For the oils usable in shock absorbers, the approximate value of the said coefficient is $0.001 \mathrm{~K}^{-1}$ [7].

If a variable orifice with a blunt needle is provided in the shock absorber (Fig. 1), the opened area of the said orifice for oil flowing during the compression and rebound strokes at a certain position of the needle shall be calculated as follows [23]:

$$
A_{3}=\frac{\pi}{4} d_{b}^{2}\left(1-\left(1-\frac{n_{c}}{2 M_{c}}\right)^{2}\right)
$$

where $d_{b}$ is the diameter of the additional orifice, $\mathrm{m} ; n_{c}$ is the click number of the variable diameter needle; $M_{c}$ is the maximum possible number of the needle clicks.

Summing forces on the floating piston, the equation of motion for the floating piston can be written as (Fig. 1):

$$
m_{2} \ddot{x}_{2}=S_{3} p_{2}-S_{3} p_{3}-F_{f 2} \operatorname{sign}\left(\dot{x}_{2}-\dot{x}_{1}\right)-m_{2} g,
$$

where $m_{2}$ is the mass of the floating piston, $\mathrm{kg} ; \ddot{x}_{2}$ is the acceleration of the floating piston, $\mathrm{m} / \mathrm{s} 2 ; S_{3}$ is the cross-section area of the gas chamber, $\mathrm{m}^{2} ; g$ is the standard acceleration due to gravity, $\mathrm{m} / \mathrm{s}^{2} ; F_{f 2}$ is the friction force appearing between the floating piston and the body of the shock absorber, $\mathrm{N}$.

Equation of motion for the main piston can be written as (Fig. 1):

$$
m_{1} \ddot{x}_{1}=S_{1} p_{1}-S_{2} p_{2}-F_{f 1} \operatorname{sign}\left(\dot{x}_{1}\right)-m_{1} g+F,
$$

where $m_{1}$ is the mass of the main piston, $\mathrm{kg} ; \ddot{x}_{1}$ is the acceleration of the piston motion, $\mathrm{m} / \mathrm{s}^{2} ; S_{1}$ is the area of the rebound chamber cross- section, $\mathrm{m}^{2} ; S_{2}$ is the area of the compression chamber cross-section, $\mathrm{m}^{2} ; F_{f 1}$ is the friction force appearing between the piston and the body of the shock absorber, N; $F$ is the damping force created by the shock absorber, $\mathrm{N}$.

Eq. 10 is used for expressing the damping force created by the shock absorber as a function of the shock absorber motion:

$$
F=m_{1} \ddot{x}_{1}-S_{1} p_{1}+S_{2} p_{2}+F_{f 1} \operatorname{sign}\left(\dot{x}_{1}\right)+m_{1} g
$$

During the compression and rebound, the damping force formed by the shock absorber consists of resistance forces, affecting the main piston in a longitudinal direction. Due to this reason, in order to obtain the expression of the damping force, firstly the equation of motion of the main piston is formed (Eq. 10). The equation of the main piston's motion on the longitudinal axis is formed by projecting the forces in corresponding directions. The directions of the operating forces depend on whether the compression or the rebound process is occurring. The mass $m_{1}$ and the acceleration $\ddot{x}_{1}$ of the main piston are put on the left side of the equation, and on the right side - the sum of all the projections of the operating forces (Eq. 10). By putting all the projections of the forces operating in the corresponding directions in the equation, and reorganising Eq. 10, the sum of all the projections of the operating forces around the main piston is obtained, which is named as the damping force formed by the shock absorber (Eq. 11).

\subsection{Shim valve mathematical model}

The shim valve model is necessary to model the oil flow rate by the orifice, which allows estimating the theoretical area for oil flowing through the piston formed by the valve deformation. In this paper, while applying the force method for shim valve modelling, it is assumed that, because of deformation of the valve during operation of the shock absorber, gaps appear between shims and the shims contact in the external radii only (Fig. 2a).

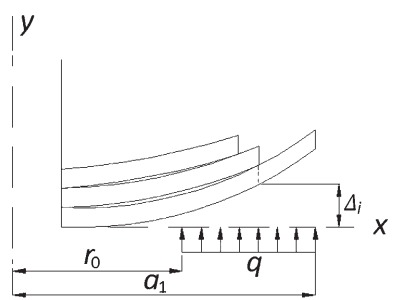

a)

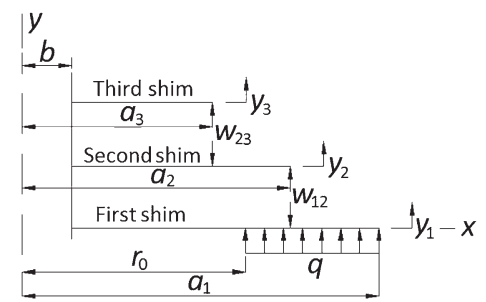

b)
Fig. 2. The scheme of a shim valve when the shims contact in the external radii only: a) the forming gaps between the shims during deformation; b) the computational scheme of the shim valve

It may be seen from the scheme presented in (Fig. 2b) that two main cases of the operating loads may be singled out:

1. Deformation of a shim is caused by the pressure difference (uniform load) appearing between the compression chamber and the rebound chamber during the operation of the shock absorber. This type of load is valid only for the first shim of the valve situated on the piston;

2. The shims of the valve are deformed by contact forces in the contact radii of the shims.

On the basis of the above-mentioned assumption and upon applying the force method, the shim valve is analysed as a statically indeterminate beam system (structure). Also the modelling is based on determining the degree of static indeterminacy and the formation of the system of the principal compatibility equations that expresses the conditions of deformation of the beam structure: 


$$
\left\{\begin{array}{c}
\delta_{11} w_{12}+\delta_{12} w_{23}+\ldots+\delta_{1 i} w_{i}+\Delta_{1}=d_{2} w_{12} \\
\delta_{21} w_{12}+\delta_{22} w_{23}+\ldots+\delta_{1 i} w_{i}=d_{3} w_{23} \\
\ldots \\
\delta_{n 1} w_{12}+\delta_{n 2} w_{23}+\ldots+\delta_{n i} w_{i}=0
\end{array}\right.
$$

where $\delta_{n i}$ is the displacement of the beam structure in the direction of the released relationship in the shim contact radius caused by the additional unit force, $\mathrm{m} ; \Delta_{i}$ is the displacement of the beam structure in the direction of the released relationship in the shim contact radius caused by the pressure difference between the working chambers of the shock absorber, $\mathrm{m} ; w_{i}$ is the support reaction (the contact force) acting in the shim contact radius, $\mathrm{N} ; d_{i}$ is the deformability coefficient of the deformed basis (a relevant shim), $\mathrm{m} / \mathrm{N}$.

The solutions of the formed compatibility equations are the values of support reactions $w_{i}$ of the released relationship, i.e. contact forces between shims of the valve that are considered unknown. Because only the first shim of the valve is deformed by the uniform load $q$ and other shims do not directly interact with the said load, the value $\Delta_{i}$ is also evaluated only in the first equation of the system (Eq. 12) that describes deformations of the first shim in the direction of the axis $y$. In the case of the first shim deformation, the deformed basis is the second shim; in the case of the second shim deformation - the third shim is deformed basis and so on. The deformability coefficient of a shim that is a deformed basis is determined in the contact radius of the shims. If the last shim of the valve is rigid, in such case a presumption that displacements of the next-to-last shim in the directions of released relationships are impossible, i.e. equal to zero (the $n$-th equation of the system (Eq. 12)) is accepted. If the $n$-th shim of the valve is movable, its deformability coefficient is determined by applying a unit force in the contact radius of shims and evaluating the deflections of the shim caused by the said force. The deformability coefficients of other shims and their combinations are determined by evaluating the relative position of the shims and their number as well as formation and application of a subsidiary system of equations (the additional forces are shown in Fig. 3):

$$
\left\{\begin{array}{c}
\delta_{22}^{\prime} w_{23}^{\prime}+\Delta_{p}=d w_{23}^{\prime} \\
\cdots \\
\delta_{n i}^{\prime} w_{i}^{\prime}+\Delta_{p-1}=d_{n-1} w_{i}^{\prime}
\end{array}\right.
$$

where $\delta_{n i}^{\prime}$ is the displacement of the beam structure in the direction of the released relationship in the contact radius of relevant shims caused by the additional unit force $\bar{w}_{i}^{\prime}, \mathrm{m} ; \Delta_{\mathrm{p}}, \Delta_{\mathrm{p}-1}$ is the displacement of a shim in shim contact radius caused by the additional unit force $\bar{w}_{i-1}^{\prime}$ applied to the external radius of the relevant shim, $\mathrm{m} ; d_{n-1}$ is the known (found) deformability coefficient of the shim, $\mathrm{m} / \mathrm{N} ; w_{i}^{\prime}$ is the support reaction caused by the additional unit force $w_{i}^{\prime}, \mathrm{N}$.

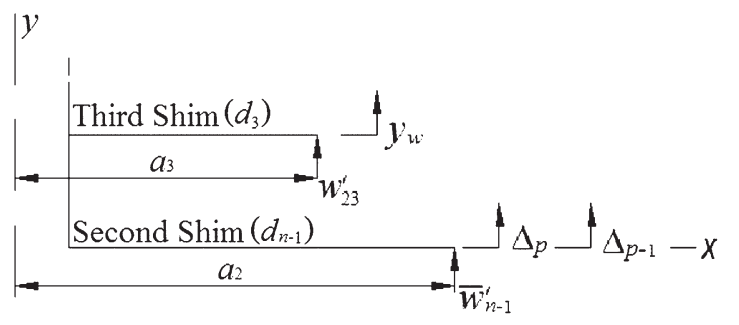

Fig. 3. The scheme for explanation of the system of equations (Eq. 13)

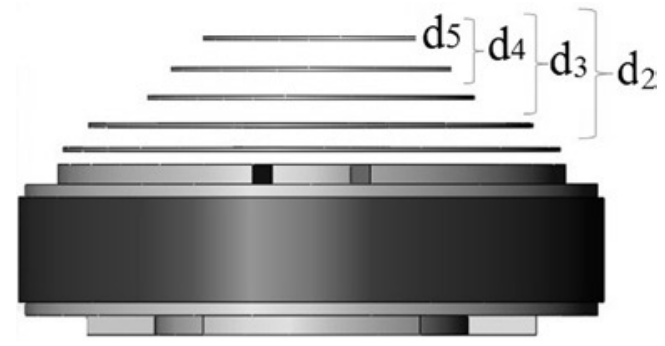

Fig. 4. The scheme for progressive determining of the deformability coefficients for each shim of the valve

Based on the system of equations (Eq. 13), the deformability coefficients for each part of the shim stack are determined progressively (Fig. 4). The deformability coefficients for each part of the shim stack are expressed by the following equation:

$$
d_{n \pm 1}=\frac{y_{w}+\Delta_{p-1}}{\bar{w}_{i}^{\prime}},
$$

where $y_{w}$ is the displacement of a relevant shim caused by the support reaction $\bar{w}_{i}^{\prime}, \mathrm{m}$.

The interdependence between the cross-section area of principal orifices of the shock absorber's piston and the radius $r_{0}$ of applying the uniform load to the first shim of the valve is expressed as follows:

$$
r_{0}=\frac{\sqrt{-\pi\left(A_{s}-\pi a_{1}^{2}\right)}}{\pi},
$$

where $A_{s}$ is the total cross-section area of orifices of the piston intended for compression or rebound stroke, $\mathrm{m}^{2} ; a_{1}$ is the external radius of the first shim of the valve, $\mathrm{m}$.

Eq. 15 is obtained by equating the cross-section area formed by all of the orifices of the main piston with the area $\pi\left(a_{1}^{2}-r_{0}^{2}\right)$ of the shim of a certain size, and in this way expressing the value from the obtained expression.

During the shock absorber's operation, the shims of the valve at any moment are affected simultaneously by more than one load (Fig. $2 b)$. Consequently, the superposition principle is applied to determine the deflections of the shims and the following system of equations is formed [26]:

$$
\left\{\begin{array}{c}
y_{1}=\left(y_{1}\right)_{q}+\left(y_{1}\right)_{12} \\
y_{2}=\left(y_{2}\right)_{12}+\left(y_{2}\right)_{23}=\left(z_{1}\right)_{q}+\left(z_{1}\right)_{12} \\
y_{3}=\left(y_{3}\right)_{23}=\left(z_{2}\right)_{12}+\left(z_{2}\right)_{23}
\end{array}\right.
$$

where $y_{1}$ is the deflection of the first shim of the valve in its external radius, $\mathrm{m} ; y_{2}$ is the deflection of the second shim of the valve in its external radius, $\mathrm{m} ; y_{3}$ is the deflection of the third shim of the valve in its external radius, $\mathrm{m} ; z_{1}$ is the deflection of the first shim of the valve in the radius of the contact of the shims, $\mathrm{m} ; z_{2}$ is the deflection of the second shim of the valve in the radius of the contact of the shims, m; $z_{3}$ is the deflection of the third shim of the valve in the radius of the contact of the shims, $\mathrm{m}$.

If a shim valve consists of more than three shims, the system of equations (Eq. 16) is supplemented with equations analogous to the second equation of this system. Application of the system of equations (Eq. 16) is described in detail in literature [26]. The theoretical area 
$A_{1}$ for oil flowing through the piston formed by the valve deformation is estimated as circumference $2 \pi a_{1}$ multiplied by valve opening height $y_{1}[8]$ :

$$
A_{1}=2 \pi \cdot a_{1} \cdot y_{1},
$$

If the initial deflection of the shim stack occurs, then, according to literature [15]:

$$
A_{1}=2 \pi \cdot a_{1} \cdot\left(y_{1}-y_{0}\right)
$$

where $y_{0}$ is the initial deflection of the shim stack in the fully closed position, $\mathrm{m}$.

It is accepted that thermal deformations of the shims do not exist. Based on the literature $[6,8,28]$, deformations of the valve shims are solved by choosing relevant algorithms from Roark's formulas for stress and strain described in the literature [27].

The described mathematical model of monotube shock absorber and its shim valve was implemented in the environment of software package MATLAB/Simulink by dividing it into interrelated subsystems. During the modelling, the unknowns are the chamber pressures, oil flow rates, the deflection of the shim stack and the damping force, so, at each time step, the said parameters are solved by applying the Eq. 4, 5, 11 and 16. Based on the literature [16], the possible value of the friction force is $30 \mathrm{~N}$.

\section{Experimental procedure}

The designed mathematical model was validated by comparison with the experimental tests results carried out on two different modified monotube shock absorbers. During the experimental tests, the damping characteristics of the shock absorbers were measured by a special electromechanical stand (Fig. 5a) that forms sinusoidal characteristics of the compression and rebound strokes of a shock absorber. Experimental tests of the modified shock absorbers were carried out at $0.03 \mathrm{~m}$ amplitude of compression/rebound strokes. The duration of a shock absorber's test was $80 \mathrm{~s}$; the maximum frequency of compressions and rebounds of the shaft of a shock absorber was $4.25 \mathrm{~Hz}$.

The nominal parameters of the tested shock absorbers and their modified shim valves used for the modelling are provided in Table 1 and Table 2, respectively. In Table 1 the symbol "*” points out that the shim is rigid in the valve and its thickness is $3.5 \mathrm{~mm}$. The Poisson's ratio $(0.28)$ and the elasticity modulus $(210 \mathrm{GPa})$ of the shim material were determined by optical emission spectrometer PMI Master Pro; the material of the valve shims is C55E carbon steel.

During modification of the shock absorbers, only new parts of good technical condition and high quality engineering maintenance materials (sealants, oil rings, oil, valve shims and so on) were used. The experimental tests of the monotube shock absorber 1 by the electromechanical stand were repeated twice, when the orifice with the blunt needle is fully opened (to fully open the orifice, 30 clicks are needed) and when the orifice with the blunt needle is fully closed ( 0 clicks) (Fig. 1). Monotube shock absorber 2 was tested when the said orifice with the blunt needle was only fully opened. In the both abovementioned shock absorbers, a symmetric piston was used (Fig. 5b).

At the initial time moment, the value of pressure in chambers of the shock absorber is $1.5 \mathrm{MPa}$. The shim clamping radius of valve shims is $8.4 \mathrm{~mm}$ (shim clamping radius is marked by symbol $b$ in Fig. 2b) in monotube shock absorber 1 and $7 \mathrm{~mm}$ - in monotube shock absorber 2 . The diameter of the variable orifice with the blunt needle is $2 \mathrm{~mm}$ when it is fully opened. All experimental tests were carried out at the temperature of $293 \mathrm{~K}$. a)

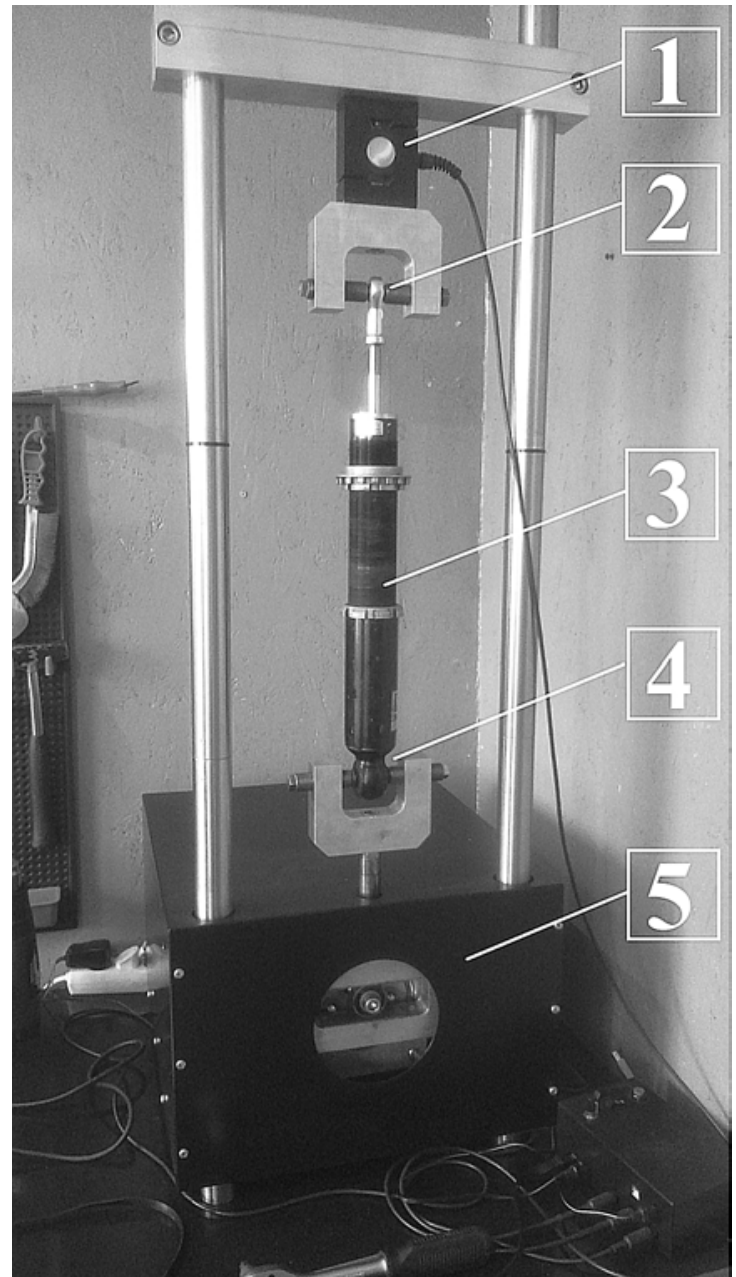

b)

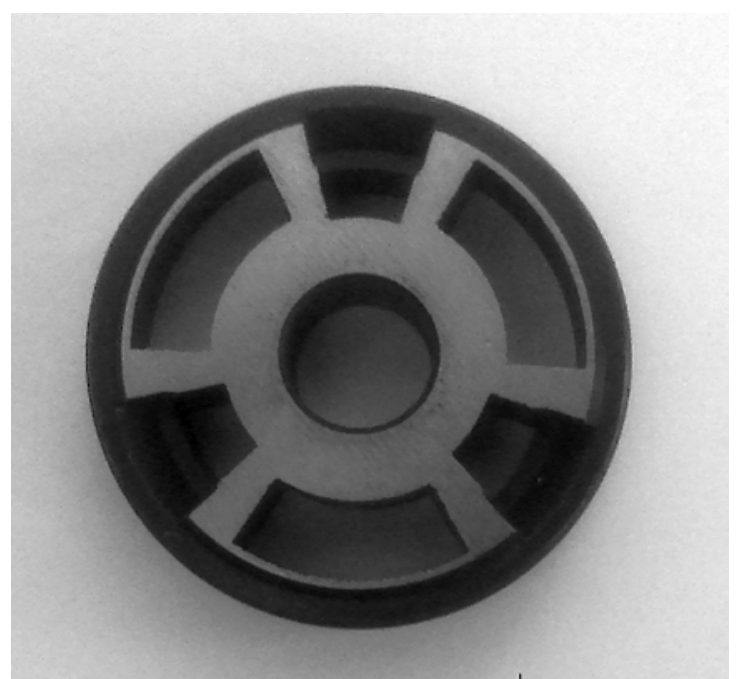

Fig. 5. The equipment used during tests: a) The shock absorber test stand used for experimental tests and the monotube shock absorber 1 mounted in it, 1 - Load cell; 2 - The upper mounting point; 3 - Monotube shock absorber 1; 4 - The lower mounting point; 5 - electromechanical test stand; b) The side of the piston of the monotube shock absorber 1 intended for the compression stroke 
Table 1. The nominal parameters of shim valve structures in the researched shock absorbers

\begin{tabular}{|c|c|c|c|c|c|c|c|c|c|c|}
\hline \multirow{4}{*}{$\begin{array}{l}\text { Monotube shock } \\
\text { absorber } 1\end{array}$} & $\begin{array}{l}\text { Position of the } \\
\text { shim }\end{array}$ & 1 & 2 & 3 & 4 & 5 & 6 & 7 & 8 & 9 \\
\hline & \multicolumn{10}{|c|}{ External radius of the shim, $\mathrm{mm}$} \\
\hline & Compression & 19 & 19 & 19 & 19 & 19 & 15 & 13 & 8.5 & 8.5 \\
\hline & Rebound & 17 & 17 & 17 & 15 & 12.5 & 8.5 & 8.5 & $8.5^{*}$ & - \\
\hline \multirow{4}{*}{$\begin{array}{l}\text { Monotube shock } \\
\text { absorber } 2\end{array}$} & $\begin{array}{l}\text { Position of the } \\
\text { shim }\end{array}$ & 1 & 2 & 3 & 4 & 5 & 6 & 7 & 8 & 9 \\
\hline & \multicolumn{10}{|c|}{ External radius of the shim, mm } \\
\hline & Compression & 17 & 15 & 12.5 & 11 & 9 & 7.5 & 7.5 & - & - \\
\hline & Rebound & 15 & 15 & 13.75 & 11 & 9 & 8.5 & 8.5 & - & - \\
\hline
\end{tabular}

Table 2. The nominal parameters of the tested shock absorbers

\begin{tabular}{|c|c|c|c|c|}
\hline \multirow[b]{2}{*}{ Shock absorber } & \multicolumn{4}{|c|}{ A parameter } \\
\hline & $\begin{array}{c}\text { Shim thickness, } \\
\text { mm }\end{array}$ & $\begin{array}{l}\text { The orifice cross-section } \\
\text { area during compression/ } \\
\text { rebound stroke, } \mathrm{mm}^{2}\end{array}$ & Oil & $\begin{array}{l}\text { The piston diameter } \\
\mathrm{mm}\end{array}$ \\
\hline $\begin{array}{l}\text { Monotube shock } \\
\text { absorber } 1\end{array}$ & \multirow{2}{*}{0.3} & $325.5 / 102.4$ & \multirow{2}{*}{$\begin{array}{c}\text { Castrol Fork Oil } \\
10 \mathrm{~W}\end{array}$} & 45 \\
\hline $\begin{array}{l}\text { Monotube shock } \\
\text { absorber } 2\end{array}$ & & $237.2 / 72.8$ & & 40 \\
\hline Shock absorber & $\begin{array}{l}\text { The shaft di- } \\
\text { ameter, mm }\end{array}$ & $\begin{array}{l}\text { Heights of compression/ } \\
\text { rebound/ } \\
\text { gas chambers, mm }\end{array}$ & $\begin{array}{l}\text { Adiabatic pro- } \\
\text { cess constant } \\
\text { for Nitrogen }\end{array}$ & $\begin{array}{l}\text { Oil Bulk modulus, } \\
\mathrm{MPa}\end{array}$ \\
\hline $\begin{array}{l}\text { Monotube shock } \\
\text { absorber } 1\end{array}$ & 20 & \multirow{2}{*}{$105 / 105 / 50$} & \multirow{2}{*}{1.4} & \multirow{2}{*}{1500} \\
\hline $\begin{array}{l}\text { Monotube shock } \\
\text { absorber } 2\end{array}$ & 12.4 & & & \\
\hline
\end{tabular}

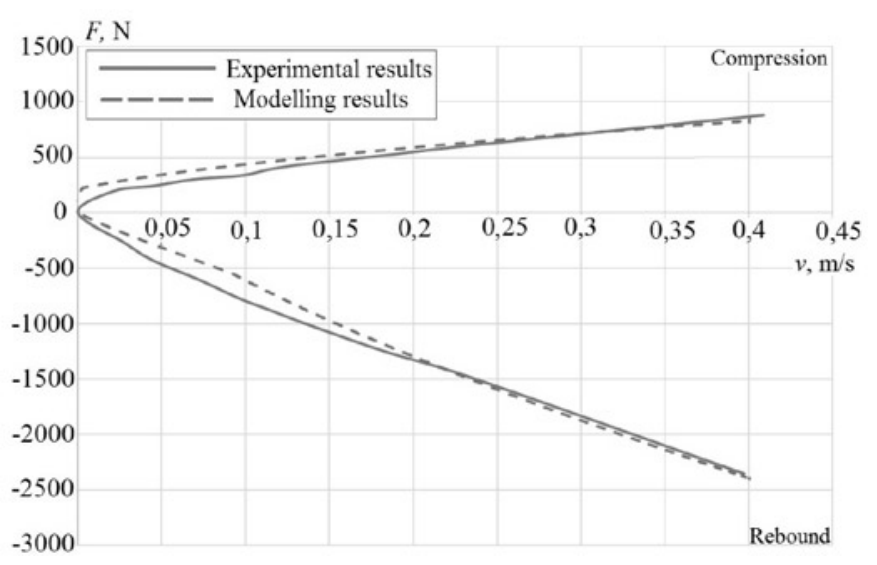

Fig. 6. The damping characteristics of the monotube shock absorber 2, when the variable orifice with the blunt needle is open shims that are in the positions 1 and 2 (Table 1.). At higher values of stiffness of the shims that are in the positions 1 and 2, the value of the damping force generated in the low speed phase is higher and the knee point is more clearly visible. A higher stiffness of a shim causes an increased preload for the shim stack and a larger pressure difference is needed across the shim stack to deflect it. When the variable orifice is open, no additional resistance to oil flowing through the said orifice is formed; in such a case, the growing of the damping force generated in the low velocity phase is linear and the knee point is not visibly expressed (Fig. 6; Fig. 7b); however, the value of the generated damping force is lower as compared to the closed orifice. For example, when the variable orifice of the monotube shock absorber 1 is closed, the maximum value of its damping force generated in the low velocity phase that was found in the experiments equals to $369 \mathrm{~N}$ and when the orifice is open - the said force equals to $128 \mathrm{~N}$ (Fig. 7). Nevertheless, an evaluation of the values of the damping force generated in the low velocity phase discloses discrepancies between the experimental

\section{Results and discussion}

The results of the damping force modelling were compared with the data of the damping force of the tested shock absorbers determined during the experimental tests and a good level of agreement was obtained. The value of the total relative error between the results of the mathematical modelling and the results of the experimental tests does not exceed $3 \%$ both for compression and rebound strokes. The types of the characteristics obtained by math- a)
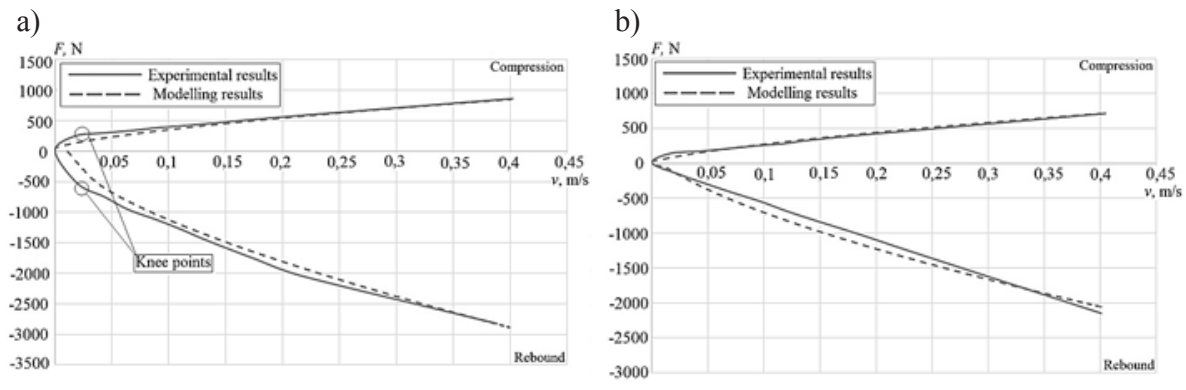

Fig. 7. The damping characteristics of the monotube shock absorber 1: a) when the variable orifice with blunt needle is closed; b) when the variable orifice with blunt needle is open 


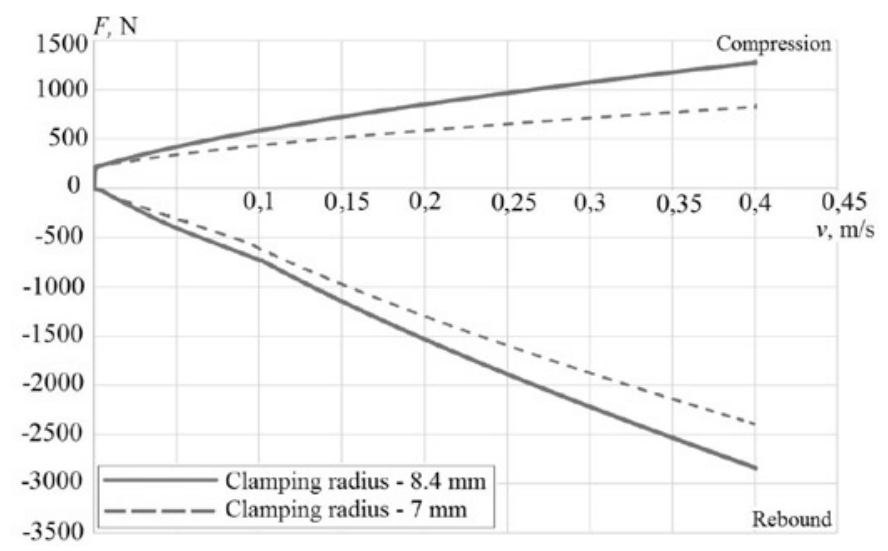

Fig. 8. The damping characteristics of the monotube shock absorber 2 at different values of the shim clamping radius

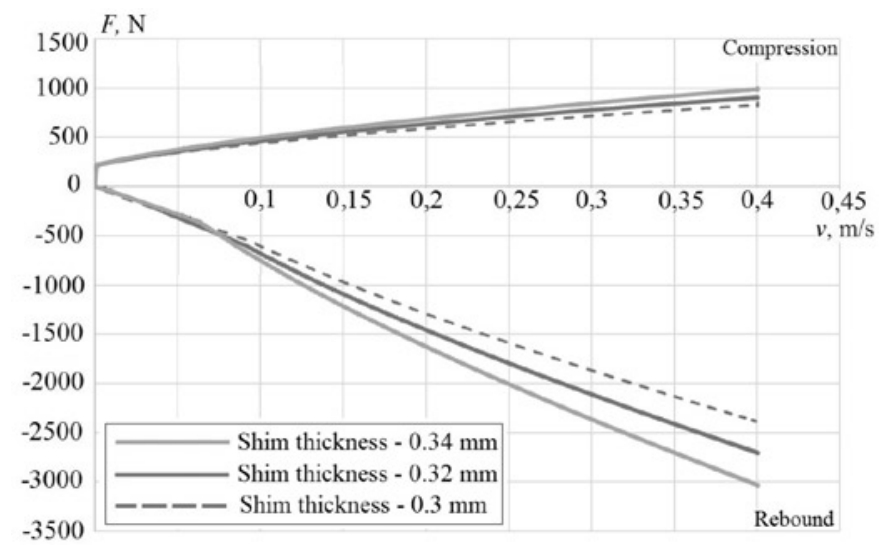

Fig. 9. The damping characteristics of the monotube shock absorber 2 at different values of the shim thicknesses

and modelling results that attain to $17.83 \%$ in some time steps. The appeared errors may be explained by an observed formation of the damping force loop in the low velocity phase, the meaning of which is close to the phenomenon of formation of hysteresis loop. During mathematical modelling, the hysteresis loop is formed because of the accepted constant friction force between elements of the shock absorber.

\subsection{Normal and high velocity phase}

During the experiment, it was found that oil flowing through the variable orifice influences also the maximum value of the damping force generated in normal $\left(0.05<\dot{x}_{1} \leq 0.2 \mathrm{~m} / \mathrm{s}\right)$ and high velocity $\left(0.2<\dot{x}_{1} \leq 0.4 \mathrm{~m} / \mathrm{s}\right)$ phase. It can be seen from Fig. 7 that when the structure of the valve is the same and the variable orifice is closed, the value of the generated damping force is $860 \mathrm{~N}$ during the compression stroke and $2890 \mathrm{~N}$ during the rebound stroke. When the orifice is open, the value of the generated damping force is $710 \mathrm{~N}$ during the compression stroke and $2050 \mathrm{~N}$ during the rebound stroke. It may be explained as follows: during damping the vibrations in the high velocity phase, the variable orifice is not closed or blocked, so the oil flowing through it during the operation of the shock absorber is constant independently from the velocity of the piston's compression/rebound. It is clear based on the obtained results that the maximum value of the generated damping force is higher when the variable orifice is closed and is lower when the orifice is open. The extent of the increase/decrease of the damping force on changing the position of the needle of the orifice during compression or rebound stroke depends on the diameter of the orifice on operation of the shock absorber and the accepted values of the discharge coefficient. A value of the damping force generated in normal/high velocity phase is influenced by the shims of the positions 3-9 (Table 1.) and their stiffness. At higher shim clamping radius (Fig. 2b), the stiffness of the shim valve is higher, so the generated damping force increases as well (Fig. 8).

During the mathematical modelling, it was also found that the shim thickness affected the stiffness of the valve and the value of the generated damping force. At higher values of the shim thickness, the generated damping force increases as well (Fig. 9).

However, the source of literature [17] points out that the stiffness of a shim is not linear in relation to its thickness. To calculate how many thin shims it takes to equal one thicker shim, the formula is approximately the same as for comparing the stiffness of dissimilar constant section beams [17]:

$$
N=\left(\frac{x_{s}}{x_{p}}\right)^{3}
$$

where $x_{s}$ is the thickness of the thicker shim, $\mathrm{m} ; x_{p}$ is the thickness of the thinner shim, $\mathrm{m}$.

Taking into account the obtained results as well as the Eq. 4 and 17 , it becomes clear that the valve $y_{1}$ and the oil flow rate $Q_{1}$ through the valve depend on the shim stack stiffness. For these reasons, it is obvious that the parameters of the shim valve and its stiffness impact considerably the damping force generated by the shock absorber.

\section{Conclusion}

This paper presents the variety of mathematical model types for monotube shock absorbers and the new method for modelling shim valves for shock absorbers is developed and proposed together with a discussion of this model performance.

Application of the force method (intended for analysing the statically indeterminate systems) allows determining the contact forces appearing between shims of the valve with a good adaptation to wide range of various parameters of shim valve. The algorithm for applying the suggested model has been clarified and detailed.

The effectiveness of the suggested model has been verified by experimental tests. The new model has demonstrated clear advantages, because the found values of the relative errors were $\leq 3 \%$ both during the compression stroke and the rebound stroke. This fact attests the created mathematical model to be correct and applicable for seeking better vehicle road holding characteristics.

In addition, the influence of the shim valve construction and the variable orifice construction on the shock absorber damping characteristics has been discussed. The obtained results confirm the relationship between the properties of all shims of the valve and the damping force generated by the shock absorber.

Acknowledgement: We wish to express our most sincere gratitude and appreciation to "We Are Dynamic" for sharing their experience in the activities related to shock absorbers modification and for the opportunity to carry out the experimental tests.

\section{References}

1. Boggs C, Ahmadian M, Southward S. Efficient empirical modeling of a high-performance shock absorber for vehicle dynamics studies. Vehicle Systems Dynamics 2009, 48(4): 481-505, http://dx.doi.org/10.1080/00423110902906292.

2. Burdzik R, Konieczny L, Piwnik J, Baranowski P. The influence of oil leak in modern vehicle shock absorber on its damping characteristics. Transport Problems 2009; 4(4): 99-106. 
3. Calvo J A, Diaz V, San Roman J 1, Garcia-Pozuelo D. Influence of shock absorber wearing on vehicle brake performance. International Journal of Automotive Technology 2008, 9(4): 467-472, http://dx.doi.org/10.1007/s12239-008-0056-z.

4. Calvo J A, Lopez-Boada B, San Roman J L, Gauchia A. Influence of a shock absorber model on vehicle dynamic simulation. Proc. of the Institution of Mechanical Engineers Part D Journal of Automobile Engineering 2009, 223(2): 189-203, http://dx.doi.org/ 10.1243/09544070JAUTO990.

5. Cui Y, Kurfess T R, Messmen M. Testing and Modeling of Nonlinear Properties of Shock Absorbers for Vehicle Dynamics Studies. Proc. of the World Congress on Engineering and Computer Science 2010, 2: 949-954.

6. Czop P, Slawik D, Sliwa P, Wszolek G. Simplified and advanced models of a valve system used in shock absorbers. Journal of Achievements in Materials and Manufacturing Engineering 2009, 33(2): 173-180.

7. Dixon J C. The Shock Absorber Handbook. Great Britain: Professional Engineering Publishing Ltd and John Wiley and Sons Ltd, 2007.

8. Farjoud A, Ahmadian M, Craft M, Burke W. Nonlinear modeling and experimental characterization of hydraulic dampers: effects of shim stack and orifice parameters on damper performance. Nonlinear Dynamics 2011, 67(2): 1437-1456, http://dx.doi.org/10.1007/s11071-011-0079-2.

9. Fernandes C, Noguchi E, Castro R, Almeida U. Influence of Shock Absorber Non-Linearities Over the Vehicle Dynamics Behaviour. SAE Technical Paper 2014-36-0018 2014: 10 pp, http://dx.doi.org/ 10.4271/2014-36-0018.

10. Haj-Kacem R B, Ouerfelli N, Herraez J V, Guettari M, Hamda H, Dallel M. Contribution to modeling the viscosity Arrhenius-type equation for some solvents by statistical correlations analysis. Fluid Phase Equilibria 2014, 383: 11-20, http://dx.doi.org/ 10.1016/j.fluid.2014.09.023.

11. Kim Y H, Bae W B, Lim D J, Suh Y S. A Study on the Development of Engineering Plastic Piston Used in the Shock Absorber. Metals and Materials 1998, 4(4): 852-858, http://dx.doi.org/10.1007/BF03026412.

12. Koylu H, Cinar A. Dynamical investigation of effects of variable damper settings induced brake pressure oscillations on axle and wheel oscillations during ABS-braking based on experimental study. Meccanica 2013, 48(5): 1093-1115, http://dx.doi.org/10.1007\%2Fs11012-012-9654-y.

13. Koylu H, Cinar A. The influences of worn shock absorber on ABS braking performance on rough road. International Journal of Vehicle Design 2011, 57(1): 84-101, http://dx.doi.org/10.1504/IJVD.2011.043598.

14. Lang H. Automotive dampers at high stroking frequency. Doctoral diss., University of Michigan, Ann Arbor, MI, 1977, 288 pp.

15. Lee K. Numerical Modelling for the Hydraulic Performance Prediction of Automotive Monotube Dampers. Vehicle Systems Dynamics 1997, 28(1): 25-39, http://dx.doi.org/10.1080/00423119708969347.

16. Lizarraga J, Sala J A, Biera J. Modelling of friction phenomena in sliding conditions in suspension shock absorber. Vehicle System Dynamics 2009, 46(1): 751-764, http://dx.doi.org/10.1080/00423119708969347.

17. Ohlins Racing AB, Inside Ohlins T44 manual. Part 1. Theory and Design [online] [accesed 10 March 2016] Available from Internet: http:// www.motorsportsspares.com/files/inside_the_tt44_theory_and_design.pdf.

18. Ping Y. Experimental and mathematical evaluation of dynamic behaviour of an oil - air coupling shock absorber. Mechanical Systems and Signal Processing 2003, 17(8): 1367-1379, http://dx.doi.org/10.1006/mssp.2002.1528.

19. Ping Y. Mechanical characteristics of oil-damping shock absorber for protection of electronic-packaging components. Tsinghua Science and Technology 2005, 10(2): 216-220, http://dx.doi.org/10.1016/S1007-0214(05)70057-2.

20. Qian X, Qinghua L, Chao C. The influence of lateral shock absorber valve parameters on vehicle dynamic performance. Journal of Mechanical Science and Technology 2015, 29(5): 1907-1911. http://dx.doi.org/10.1007\%2Fs12206-015-0412-7.

21. Reybrouck K. A nonlinear parametric model of an automotive shock absorber. SAE Technical Paper $9408691994: 10$ pp, http://dx.doi. org/10.4271/940869.

22. Rhoades K S. Development and experimental verification of a parametric model of an automotive damper. Master's thesis, Texas A\&M University, Canyon, TX, 2006, 126 pp.

23. Shim ReStackor, Needle Geometry [online] [accesed 24 October 2015] Available from Internet:http://www.shimrestackor.com/Code/User_ Manual/Sections/Input/Aux_Comp/Needle_Geom/needle-geom.htm.

24. Simms A, Crolla D. The Influence of Damper Properties on Vehicle Dynamic Behaviour. SAE Technical Paper 2002-01-0319 2002: 14 pp, http://dx.doi.org/10.4271/2002-01-0319.

25. Skačkauskas P, Žuraulis V. Research of characteristics of sports cars' shock absorbers. Proc. 19th International Conference Transport Means 2015: 231-235.

26. Talbott M S, Starkey J. An Experimentally Validated Physical Model of a High-Performance Mono-Tube Damper. SAE Technical Paper 2002-01-3337 2002: 20 pp, http://dx.doi.org/10.4271/2002-01-3337.

27. Young W C, Budynas R G. Roark's Formulas for Stress and Strain. New York: McGraw-Hill, 2001.

28. Yukimasa T, Motohashi H, Ohtaki M, Chikamori H. Comments on Oil Seals for Gas Pressurized Shock Absorbers of Automotive Suspensions, SAE Technical Paper 850333 1985: 12 pp, http://dx.doi.org/10.4271/850333.

29. Žuraulis V, Levulytė L. The Influence of Comfort and Sport Driving Modes of Modern Vehicles on the Vibration of Sprung and Unsprung Masses. Proc. 18th International Conference Transport Means 2014: 15-19.

Paulius SKAČKAUSKAS

Vidas ŽURAULIS

Vaidas VADLUGA

Saulius NAGURNAS

Department of Automobile Transport

Vilnius Gediminas Technical University

Basanavičiaus str., 28 LT-03224 Vilnius, Lithuania

E-mails: paulius.skackauskas@vgtu.It,vidas.zuraulis@vgtu.It, vaidas.vadluga@vgtu.It, saulius.nagurnas@vgtu.lt 